Western University

Scholarship@Western

Inspiring Minds - Showcasing Western's Graduate Research, Scholarship and Creative Activity

September 2021

Developing More Accurate Models of Tornados

Niall C. Bannigan

Western University, nbanniga@uwo.ca

Follow this and additional works at: https://ir.lib.uwo.ca/inspiringminds

Citation of this paper:

Bannigan, Niall C., "Developing More Accurate Models of Tornados" (2021). Inspiring Minds - Showcasing Western's Graduate Research, Scholarship and Creative Activity. 48.

https://ir.lib.uwo.ca/inspiringminds/48 


\section{Developing More Accurate Models of Tornados}

Tornados seem to be touching down more frequently in Ontario recently and, though not as large as those in places like Oklahoma, are a reminder that we live in tornado alley. Therefore, it is crucial that we understand the key characteristics of tornados by creating model versions of them and testing our infrastructure's ability to withstand them. However, current models still use assumptions based on work from the 1970's that underestimate the destructive potential of tornados, leaving homes inadequately prepared. In sophisticated modern tornado simulations, I have observed movement over many kilometres and dramatic wobbling like a spinning top. With a novel method to track this motion, I have identified dangerous wind speeds over 1.3 times greater and two times further from the tornado centre than previous models predict. My work will provide more accurate modelling and tracking methods to improve infrastructure design for protection against tornados.

Word Count: 147 